\section{BMJ Open} Ophthalmology

\title{
Inverted papilloma of the conjunctiva
}

\author{
Ingvild Ramberg, ${ }^{1,2}$ Nicolai Christian Sjö, ${ }^{1}$ Jesper Hansen Bonde, ${ }^{3}$ \\ Steffen Heegaard ${ }^{\oplus 1,2}$
}

To cite: Ramberg I, Sjö NC, Bonde $\mathrm{JH}$, et al. Inverted papilloma of the conjunctiva. BMJ Open Ophthalmology 2019;4:e000193. doi:10.1136/ bmjophth-2018-000193

Received 4 July 2018 Revised 24 October 2018 Accepted 9 January 2019
Check for updates

(c) Author(s) (or their employer(s)) 2019. Re-use permitted under CC BY-NC. No commercial re-use. See rights and permissions. Published by BMJ.

${ }^{1}$ Department of Pathology, Section for Eye Pathology, Copenhagen University Hospital Rigshospitalet, Copenhagen, Denmark

${ }^{2}$ Department of Ophthalmology, Copenhagen University Hospital Rigshospitalet, Copenhagen, Denmark

${ }^{3}$ Department of Pathology, Molecular Pathology Laboratory, Copenhagen University Hospital Hvidovre, Copenhagen, Denmark

\section{Correspondence to} Dr Steffen Heegaard; sthe@ sund.ku.dk

\section{ABSTRACT}

Objective The purpose of the present study is to describe the clinical and histopathological features of conjunctival inverted papilloma, to analyse for the presence of human papillomavirus (HPV), and to determine if HPV infection is associated with this type of tumour and its inverted growth pattern.

Methods and Analysis Cases of conjunctival inverted papillomas were retrieved from the archives of the Department of Pathology, Rigshospitalet, Denmark. Patient records and pathology reports were reviewed. Formalinfixed and paraffin-embedded tissue was analysed for the presence of HPV by immunohistochemistry, in situ hybridisation (ISH), PCR and HPV typed by sequencing. Results A total of four cases were retrieved. The age at diagnosis ranged from 41 to 77 years, with an equal sex distribution. All lesions were localised to the bulbar conjunctiva and two of the cases were pigmented. Histopathological examination did not reveal areas of dysplasia. All lesions were p16-positive and p53positive by immunohistochemistry. High-risk HPV 58 was demonstrated in one lesion by ISH and PCR.

Conclusion Here we present four cases of conjunctival inverted papilloma, which is an exceedingly rare tumour with only 11 previously reported cases in the literature. Both clinically and histopathologically, the tumours show distinct features compared with exophytic conjunctival papillomas. Furthermore, this is the first description of high-risk HPV 58 in a conjunctival tumour. The biological behaviour of the tumour is uncertain due to its rareness. However, a complete removal of the lesion and a careful observation are recommended. The finding of HPV 58 underlines the necessity of this precaution.

\section{INTRODUCTION}

Papillomas are benign epithelial lesions of the mucous membranes. Conjunctival papillomas are histopathologically divided into exophytic and inverted papillomas. The inverted papilloma consists of folds of papillomatous epithelium that invaginate into the underlying stroma, rather than growing in a purely exophytic fashion that is characteristic of the far more common exophytic squamous papilloma. In the neighbouring regions, inverted papilloma usually originates in the nasal cavity and paranasal sinuses. ${ }^{2}$

Inverted conjunctival papilloma is exceedingly rare. To date, only 11 cases of inverted conjunctival papilloma have been reported. ${ }^{3-10}$ Due to its rareness, the aetiology

\section{Significance of the study}

\section{What is already known about this subject?}

Inverted papilloma of the conjunctiva is an exceedingly rare tumour.

Due to the rarity, the biology and malignant potential of these tumours are uncertain.

\section{What are the new findings?}

$>$ Here we describe the clinical and histopathological features of the tumours in the largest published series to date and have furthermore found an association between the tumour and high-risk human papillomavirus.

How might these results change the focus of research or clinical practice?

The finding of high-risk human papillomavirus in our series, and thereby a risk of malignant transformation, underlines the necessity of complete excision and careful observation of these tumours.

and underlying biology are uncertain. Recurrence and malignant transformation occurred in 2 of the 11 cases described. ${ }^{510}$

Low-risk human papillomavirus (LR-HPV) is associated with the occurrence of exophytic conjunctival papilloma. ${ }^{11} \mathrm{HPV}$ is a DNA virus with a double-stranded DNA genome, and variations in the DNA sequence define the more than 200 different genotypes, ${ }^{12}$ typically stratified into two groups targeting either the mucosal or cutaneous tissue (International Agency for Research on Cancer [IARC] Monograph, 2012). The IARC has defined 13 HPV genotypes as carcinogenic to humans based on sufficient evidence of carcinogenicity, hereafter referred to as high-risk HPV (HR-HPV).

The purposes of the present study are to describe the clinical and pathological features of conjunctival inverted papillomas, and furthermore to determine if HPV is associated with this tumour type and its inverted growth pattern.

\section{MATERIALS AND METHODS}

\section{Sample selection}

Cases of inverted conjunctival papillomas were retrieved from the archives of the Eye Pathology Section, Department of Pathology, 
Rigshospitalet, which is the centralised, national ophthalmic pathology laboratory in Denmark. Histological review of the original diagnosis was performed for each specimen to confirm the diagnosis. Formalin-fixed and paraffin-embedded (FFPE) specimens were collected. Clinical and histopathological data including age, sex, localisation, duration of symptoms, clinical appearance, recurrence, treatment and histopathological features were gathered from the referring ophthalmologist and from pathology reports.

\section{Immunohistochemistry}

P16 immunohistochemistry (IHC) was performed as supplement and surrogate marker of HPV infection. ${ }^{13}$ P53 IHC was performed as an indicator of ultraviolet-induced tumour growth. ${ }^{14}$ IHC was performed on a Ventana BenchMark ULTRA IHC/ISH Staining Module (Ventana Medical Systems, Tucson, Arizona, USA) according to the manufacturer's recommendations. P16 was detected by incubating sections with monoclonal mouse antibody CINtec p16 clone E6H4, and p53 was detected with monoclonal mouse antibody clone DO7 (both Roche Diagnostics). Slides were counterstained with haematoxylin. The threshold of p16 positivity was $>70 \%$ positive nuclear and cytoplasmic staining with medium to strong intensity. ${ }^{13}$ Marked p53 accumulation of at least 20\% cell staining has been considered positive, according to Nordic Immunohistochemical Quality Control (http:// www.NordiQC.org; Aalborg University Hospital).

\section{In situ hybridisation}

In situ hybridisation (ISH) for high-risk HPV DNA types $16,18,31,33,35,39,45,51,52,56,58$ and 66 was performed by Inform HPV III Family 16 Probe (Ventana Medical Systems) according to the manufacturer's guidelines using a BenchMark automated slide staining system (Ventana Medical Systems). The specimens were dichotomously classified as positive or negative.

\section{DNA extraction and detection of type-specific HPV}

DNA extraction from FFPE was done using a $10 \mu \mathrm{m}$ tissue section of the archival material. Proteinase K treatment and subsequent DNA extraction were performed using the QIAamp DNA FFPE extraction kit and the QIAcube extraction unit (both Qiagen, Hilden, Germany) in concordance with the manufacturer's specifications.

\section{HPV detection: nested PCR assay}

Nested PCR with PGMY 09/11 L1 consensus primers and GP5+/GP6+ L1 consensus primers was used to analyse the extracted DNA samples as previously described by Rusan et al. ${ }^{15}$ Briefly, PCR reactions with PGMY 09/11 primers were performed in the first reaction and GP5+/GP6+ primers in the second reaction. Samples were run in duplicate. HPV plasmids for HPV 6, HPV 16 and HPV 18 were used as positive controls. Negative controls consisted of $5 \mu \mathrm{L}$ of diethyl pyrocarbonate (DEPC)-treated $\mathrm{H}_{2} \mathrm{O}$, instead of template. The RNase $\mathrm{P}$ housekeeping gene was used to verify that amplifiable
DNA was present in all DNA extracts (TaqMan RNase P detection kit, Applied Biosystems). Positive samples were run on a 2\% agarose gel, extracted using the QIAquick Gel Extraction Kit (Qiagen) and sent for sequencing to Eurofins MWG Operon. The positive and negative controls used in the PCR reaction were also run on the gel, and the positive controls were extracted and sent for sequencing. The one positive sample, along with several negative samples, was reanalysed to check for consistency.

\section{HPV detection: CLART HPV2 clinical array}

The CLART Human Papillomavirus 2 Kit (Genomica, Madrid, Spain) is a clinically validated HPV assay that can be used on multiple types of sample types. CLART2 is a low-density microarray system that individually detects 35 clinically relevant HPV types $(6,11,16,18,26,31,33,35$, $39,40,42,43,44,45,51,52,53,54,56,58,59,61,62,66$, $68,70,71,72,73,81,82,83,84,85$ and 89$) \cdot{ }^{15-17}$ Detection of HPV genotypes was achieved by PCR amplification of a 465 base pair fragment within the L1 region as previously described. ${ }^{18}$ The assay includes a control for the presence of genomic DNA (amplification of the human cystic fibrosis transmembrane conductance regulator [CFTR] gene) and an amplification control (amplification of a CFTR plasmid). ${ }^{15}$ Interpretation of the results was performed automatically by a Clinical Array Reader.

\section{RESULTS}

Four cases of conjunctival inverted papillomas were retrieved from our files. Review of the patient journals and pathology files revealed a range of age at diagnosis from 41 to 77 years, with an equal sex distribution. The duration of the symptoms ranged from 1 year to more than 20 years. Two of the lesions were clinically mistaken for being a nevus due to the pigmented appearance (figure 1A). Three of the lesions were localised to the medial bulbar conjunctiva and one localised to the lateral limbus. All the cases were treated with complete excision without adjuvant therapy. Histopathological examination showed the invagination of the conjunctival epithelium into the stroma (figure 1B,C), and re-examination did not disclose any areas of intraepithelial dysplasia or invasiveness. None of the lesions recurred or progressed to malignancy within the follow-up time (minimum of 4 years). Clinical and histopathological information is listed in table 1.

All tumours were positive in p53 IHC and one tumour was positive in p16 IHC (table 2, figure 1D,E).

Two of the four specimens were excluded from PCR due to insufficient tissue and DNA. HR-HPV 58 was identified by both PCR and CLART in one of the two inverted conjunctival papillomas available for PCR analysis (figure 1F). The same specimen was also positive by DNA ISH, whereas the three other tumours were HPV-negative using ISH. 


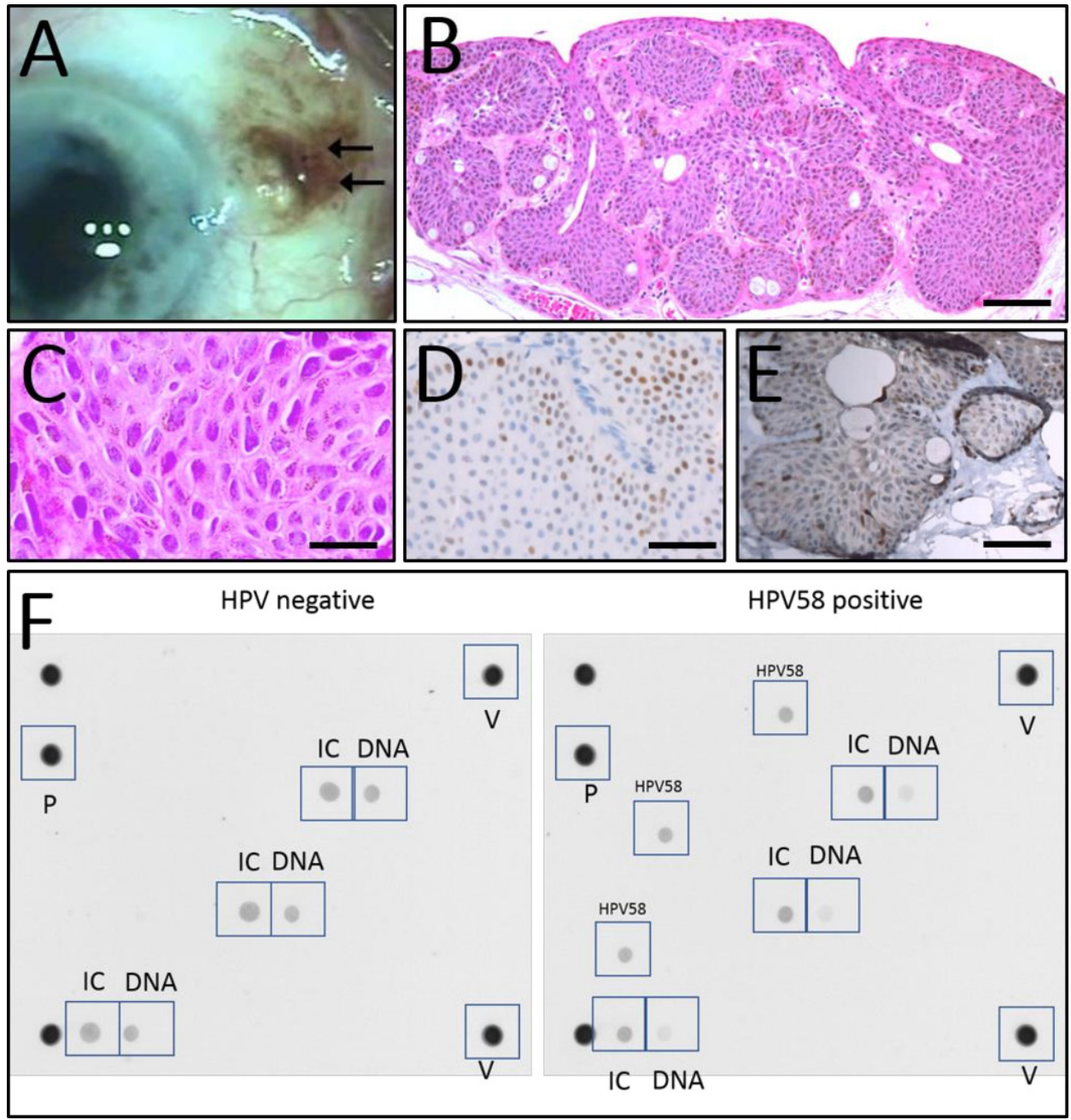

Figure 1 (A) Inverted papilloma of the conjunctiva on the medial bulbar conjunctiva in a 77-year-old woman, clinically mistaken for a nevus due to the pigmented appearance (arrows). (B) The epithelium of the inverted conjunctival papilloma invaginates into the underlying stroma with no signs of dysplasia (H\&E, scale bar=100 $\mu \mathrm{m})$. (C) A higher magnification of the tumour reveals no cellular atypia (H\&E, scale bar=20 $\mu \mathrm{m})$. (D) Nuclear staining of p53, particularly in the basal epithelial layers of the tumour (scale bar $=50 \mu \mathrm{m}$ ). (E) Diffuse overexpression of p16 with medium intensity in the tumour tissue (scale bar=70 $\mu \mathrm{m}$ ). (F) The figure shows one HPV-negative and one HPV 58-positive sample. P, positioning control to ensure correct positioning of the array in the automated reader; $\mathrm{V}$, visualisation control to ensure correct visualisation levels on the array; IC, internal control (spiked rhesus CFTR plasmid, amplicon $\approx 1200 \mathrm{bp}$ ), control for adequate PCR amplification; DNA, control for sample adequacy (human CFTR gene detection, amplicon $\approx 800 \mathrm{bp}$ ); HPV 58, specific probe reaction to PCR amplification of HPV 58 in the sample (amplicon $\approx 450 \mathrm{bp}$ ). bp, base pair; CFTR, cystic fibrosis transmembrane conductance regulator; HPV, human papillomavirus.

\section{DISCUSSION}

The previously reported cases of inverted conjunctival papillomas have shown a broad variety regarding the clinical appearance, in accordance to our results. Inverted papillomas are described as pigmented, partly pigmented or completely unpigmented lesions, enlarging over a few months to several years and affecting females and males equally. ${ }^{3-10}$ Yet it is worth noticing that pigmentation of the papilloma by clinical evaluation has been described in 5 out of 15 lesions, in contrast to exophytic papilloma where pigmentation is rarely described. In the present series, this correlates to the histopathological finding of hyperpigmentation of the basal layers of the epithelium. The localisation of the lesions is scattered all over conjunctiva, however more frequently reported in the nasal part of the conjunctiva, which is seen in 10 out of 15 reported cases. Ten out of 15 cases were epibulbar. Unlike exophytic papillomas which are most often localised inferiorly, a superior location is more common in inverted papillomas (table 1). All present cases have been treated exclusively by surgical removal. This is the case also in previously reported cases, except in two cases where adjuvant cryotherapy and neoadjuvant local chemotherapy with Mitomycin were applied. ${ }^{810}$ In table 3, we have summarised the clinical characteristics of inverted conjunctival papillomas compared with the exophytic papillomas.

Histopathologically, no lesion has been reported with a keratinising epithelium, which was also the finding in the present cases. None of the present cases showed cellular 


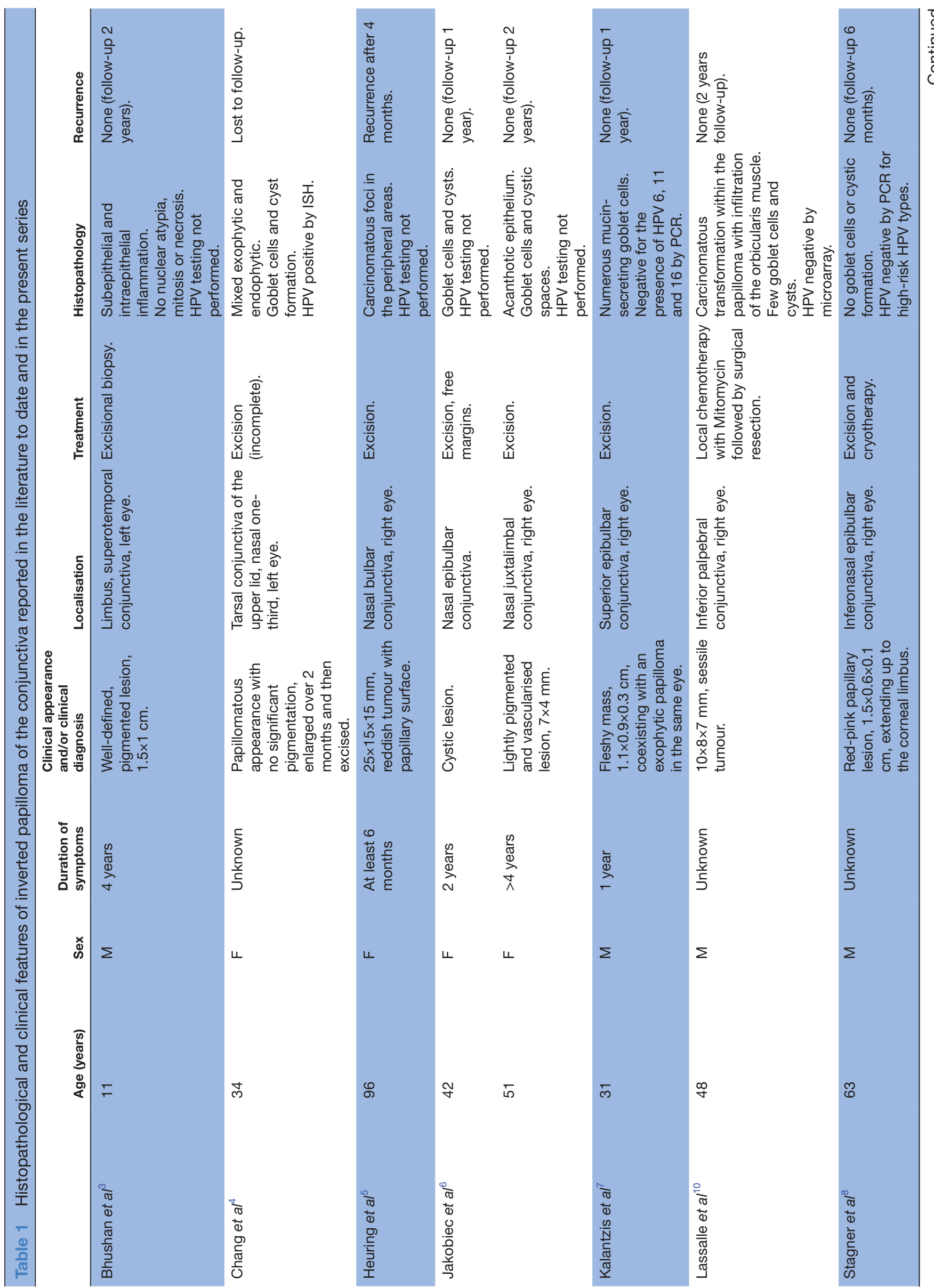




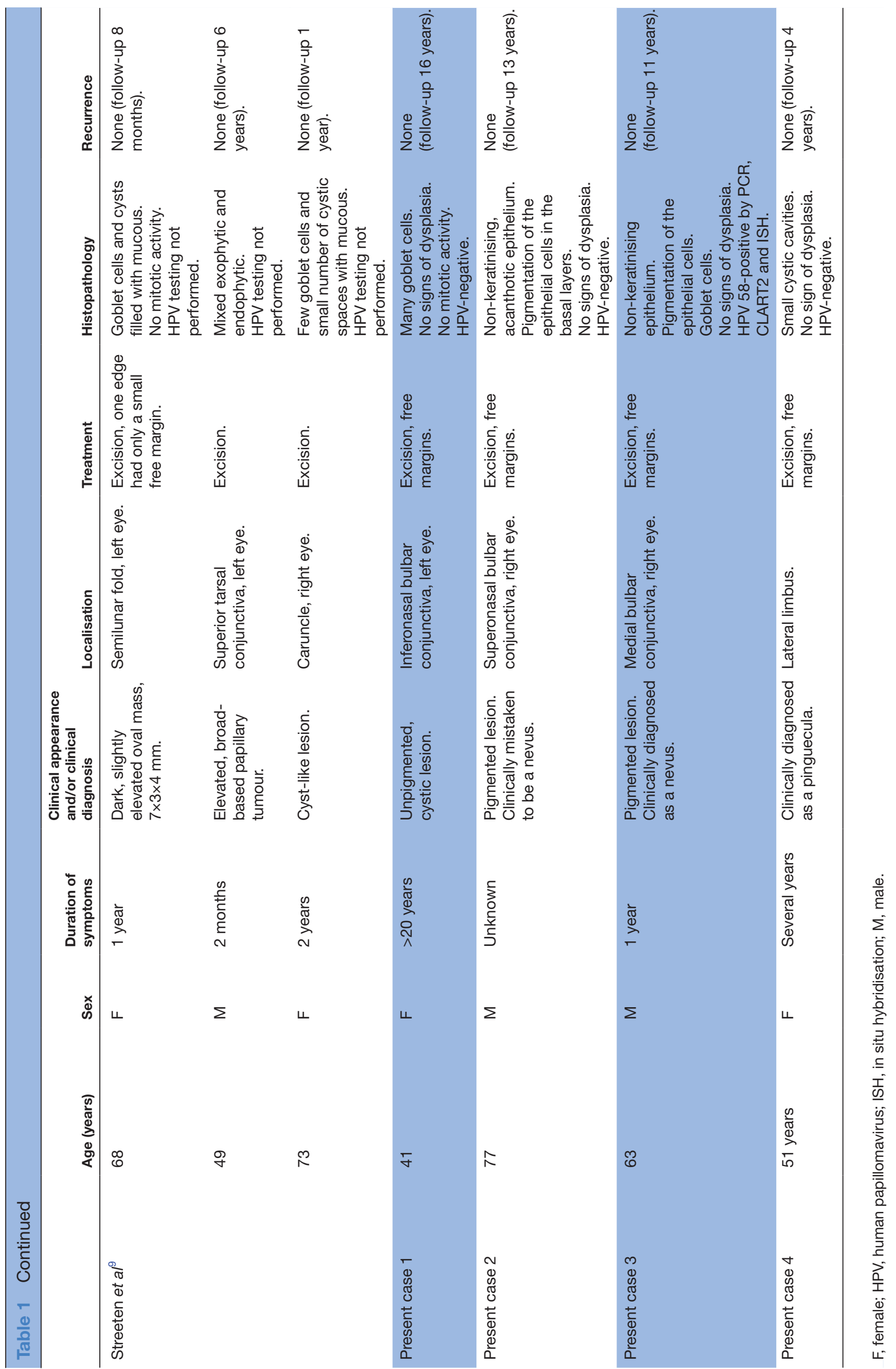


Table 2 Results of the HPV analyses

\begin{tabular}{|c|c|c|c|c|c|}
\hline Present case & P16 IHC* & P53 IHC** & In situ hybridisation & $\beta$-globin & PCR \\
\hline 1 & Negative & Positive & Negative & Negative & NA \\
\hline 2 & Negative & Positive & Negative & Positive & Negative \\
\hline 3 & Positive & NA & Positive & Positive & HPV 58-positive \\
\hline 4 & Negative & Positive & Negative & Negative & NA \\
\hline
\end{tabular}

* Nuclear and cytoplasmic staining of tumor cells by immunohistochemistry. ** Nuclear staining of tumor cells by immunohistochemistry. HPV, human papillomavirus; IHC, immunohistochemistry; NA, not available; PCR, polymerase chain reaction.

atypia, dysplasia or invasive growth. However, of 11 previously reported cases in the literature, 2 showed an aggressive behaviour. ${ }^{510}$ Both of these conjunctival papillomas had carcinomatous foci at the time of diagnosis, and one of them recurred 4 months after primary excision. ${ }^{5}$ Studies of the regionally close sinonasal mucosa have shown that at least $15 \%$ of all cases of sinonasal papillomas have developed synchronously or metachronously squamous cell carcinoma, ${ }^{2}$ and that sinonasal inverted papillomas are more often associated with development of recurrence, worsening of dysplasia and development of malignancy compared with exophytic papillomas. ${ }^{19}$

All the cases available to p53 IHC (one missing due to lack of tumour tissue) were positive. There is a hypothesis that p53 overexpression correlates with ultraviolet-induced tumour growth ${ }^{14}$; however, it is not a specific marker, and in concordance with a previous reported case of conjunctival inverted papilloma the p53 expression in our series is lower than the expression frequently seen in carcinoma of the conjunctiva.

In the present study, we have shown HR-HPV 58 in one of two investigated conjunctival inverted papillomas available for PCR analysis. This lesion was also positive by p16 IHC and HPV-positive by ISH. This is, to our knowledge, the first study demonstrating the presence of an HR-HPV 58 in a conjunctival lesion. A test for the presence of HPV

\begin{tabular}{|c|c|c|}
\hline & $\begin{array}{l}\text { Inverted } \\
\text { papilloma }^{3-10}\end{array}$ & $\begin{array}{l}\text { Exophytic } \\
\text { papilloma }^{20}\end{array}$ \\
\hline Age (mean, range) & 53.2 years $(11-85)$ & 39.6 years $(17-84)$ \\
\hline Sex & $\begin{array}{l}\text { Even gender } \\
\text { distribution }\end{array}$ & $\begin{array}{l}\text { Male } \\
\text { predominance }\end{array}$ \\
\hline Appearance & $\begin{array}{l}\text { Commonly } \\
\text { pigmented }\end{array}$ & Rarely pigmented \\
\hline Localisation & $\begin{array}{l}\text { Most often nasal } \\
\text { and superiorly }\end{array}$ & $\begin{array}{l}\text { Most often nasal, } \\
\text { inferiorly and at } \\
\text { the caruncle }\end{array}$ \\
\hline Malignancy & $\begin{array}{l}\text { Described in } 2 \text { of } \\
15 \text { at the time of } \\
\text { diagnosis }\end{array}$ & $\begin{array}{l}\text { Synchronous } \\
\text { carcinoma rare }\end{array}$ \\
\hline $\begin{array}{l}\text { Human } \\
\text { papillomavirus } \\
\text { (HPV) }\end{array}$ & $\begin{array}{l}2 \text { of } 6 \text { of tested } \\
\text { lesions HPV- } \\
\text { positive }\end{array}$ & $\begin{array}{l}\text { Strongly } \\
\text { associated with } \\
\text { low-risk HPV types }\end{array}$ \\
\hline
\end{tabular}

has been done in 4 of the 11 reported cases of inverted conjunctival papillomas. ${ }^{47810} \mathrm{HPV}$ was detected in one case, but the viral genotype was in that case not determined. ${ }^{4}$

In the more common exophytic conjunctival papilloma, there is a strong association to HPV, as HPV has been detected in $81 \%-92 \%$ in large case series. ${ }^{11} 20$ LR-HPV 6 and 11 are the most common types detected in these lesions, in accordance to their benign clinical nature. Only rarely, there are reported high-risk subtypes 16,33 and 45 in exophytic conjunctival papilloma. ${ }^{1120-22}$ These oncogenic HPV types are more often detected in epithelial malignant lesions of the conjunctiva, although the aetiological role of the virus in conjunctival squamous cell carcinoma remains controversial.

In sinonasal inverted papilloma, LR-HPV 6 and 11 and HR-HPV 16, 18 and 57 have been demonstrated. ${ }^{23}$ However, the detection rate is highly variable, with a reported range of $0 \%-100 \% .{ }^{19}{ }^{24}$ The possible oncogenic role of HPV in the progression of sinonasal inverted papillomas has been proposed in many studies. ${ }^{25}$

Different theories may explain why the presence of HPV differs in inverted and exophytic papillomas. First, the hyperkeratotic superficial epithelium of exophytic papillomas is susceptible for HPV replication because reinfection of the papilloma by assembled virions may occur. In contrast, inverted papillomas tend to be non-keratinising, and as superficial epithelium is shed, HPV is lost, accounting for the lower detection rate. ${ }^{19}$ Second, HPV assays used for these types of studies are most often without defined clinical cut-offs, rendering any analysis dependent on the performing laboratory's ability to run high-definition HPV assays. Here, we use a well-characterised, quality-controlled, clinical HPV array assay with a WHO Laboratory Network proficiency study-validated detection of all 13 HR-HPV genotypes plus HPV 6 and $11 .^{26}$ Therefore, the inability to detect HPV DNA does not necessarily abolish a viral role in the tumour development of inverted papillomas.

In conclusion, HR-HPV 58 was identified in one of two inverted conjunctival papillomas with a successful DNA extraction. To our knowledge, this is the first study demonstrating HPV 58 in a conjunctival papilloma. HPV 58 is characterised as a high-risk HPV due to its oncogenic potential in other tissue types. Due to the rarity of inverted conjunctival papilloma, their biological 
behaviour is uncertain. However, since HPV 58 has a significant oncogenic potential and because of the high incidence of recurrence and association to malignancy of inverted papilloma in the neighbouring sinonasal region, inverted papillomas of the conjunctiva should be removed completely and the patients carefully observed. Our finding of HR-HPV 58 underlines the necessity of this precaution.

Contributors IR: contributed to data collection and interpretation, and manuscript drafting. NCS: contributed to conception and design, data collection, and manuscript drafting. JHB: contributed to data analysis and interpretation, and has revised the manuscript critically. $\mathrm{SH}$ : contributed to conception, design and data interpretation, and has revised the manuscript critically. All authors have approved the final version of the manuscript.

Funding This study was supported by Arvid Schrøder and Ketty Lydia Larsen Schrøder Foundation, the Synoptik Foundation, and the Danish Eye Research Foundation.

Competing interests IR: none declared. NCS: none declared. JHB attended meetings with various HPV device manufacturers. JHB has received honoraria from Hologic/Gen-Probe, Roche, Qiagen, Genomica and BD Diagnostics for lectures. Hvidovre Hospital has ongoing contracts with BD Diagnostics, Genomica, SelfScreen and EU Horizon 2020. SH: none declared.

Patient consent for publication Not required.

Ethics approval The study was conducted according to the Declaration of Helsinki, and was approved by the Regional Scientific Ethics Committee of the Capital Region, Denmark (H-16044879) and the Danish Data Protection Agency (RH-2013-30-1035).

Provenance and peer review Not commissioned; externally peer reviewed.

Open access This is an open access article distributed in accordance with the Creative Commons Attribution Non Commercial (CC BY-NC 4.0) license, which permits others to distribute, remix, adapt, build upon this work non-commercially, and license their derivative works on different terms, provided the original work is properly cited, appropriate credit is given, any changes made indicated, and the use is non-commercial. See: http://creativecommons.org/licenses/by-nc/4.0/.

\section{REFERENCES}

1. Heegaard S, Grossniklaus H. Eye pathology - an illustrated guide. Berlin Heidelberg: Springer, 2015: 50-2.

2. Buchwald $\mathrm{C}$, Lindeberg $\mathrm{H}$, Pedersen $\mathrm{BL}$, et al. Human papilloma virus and p53 expression in carcinomas associated with sinonasal papillomas: a Danish epidemiological study 1980-1998. Laryngoscope 2001:111:1104-10.

3. Bhushan G, Raina UK, Gupta A, et al. Inverted mucoepidermoid papilloma of conjunctiva in a child. J Aapos 2015;19:266-7.

4. Chang T, Chapman B, Heathcote JG. Inverted mucoepidermoid papilloma of the conjunctiva. Can J Ophthalmol 1993;28:184-6.

5. Heuring $\mathrm{A}$, Hütz $\mathrm{W}$, Eckhardt $\mathrm{H}$, et al. Invertiertes Transitionalzellpapillom Der Bindehaut MIT peripherer karzinomatöser Entartung. Klin Monbl Augenheilkd 1998;212:61-3.

6. Jakobiec FA, Harrison W, Aronian D. Inverted mucoepidermoid papillomas of the epibulbar conjunctiva. Ophthalmology 1987;94:283-7.

7. Kalantzis G, Papaconstantinou D, Georgalas I, et al. Different types of conjunctival papilloma presenting in the same eye. Orbit 2010;29:266-8.
8. Stagner AM, Jakobiec FA, Chi A, et al. Conjunctival inverted squamous papilloma: a case report with immunohistochemical analysis and review of the literature. Surv Ophthalmol 2015;60:263-8.

9. Streeten BW, Carrillo R, Jamison R, et al. Inverted papilloma of the conjunctiva. Am J Ophthalmol 1979;88:1062-6.

10. Lassalle S, Maschi C, Caujolle JP, et al. Inverted conjunctival papilloma: a certainly underestimated high-risk lesion for carcinomatous transformation-a case report. Can J Ophthalmol 2017; 52: 30 -1.

11. Sjö NC, Heegaard S, Prause JU, et al. Human papillomavirus in conjunctival papilloma. Br J Ophthalmol 2001;85:785-7.

12. Bravo IG, Félez-Sánchez M. Papillomaviruses: viral evolution, cancer and evolutionary medicine. Evol Med Public Health 2015;2015:32-51.

13. Fakhry C, Lacchetti C, Perez-Ordonez B. Human papillomavirus testing in head and neck carcinomas: ASCO clinical practice guideline endorsement summary of the cap guideline. $J$ Oncol Pract 2018;14:613-7.

14. Pontén F, Berne B, Ren ZP, et al. Ultraviolet light induces expression of p53 and p21 in human skin: effect of sunscreen and constitutive p21 expression in skin appendages. $J$ Invest Dermatol 1995;105:402-6.

15. Rusan M, Klug TE, Henriksen JJ, et al. Prevalence of tonsillar human papillomavirus infections in Denmark. Eur Arch Otorhinolaryngol 2015;272:2505-12.

16. Ejegod DM, Rebolj M, Bonde J. Comparison of analytical and clinical performance of CLART HPV2 genotyping assay to linear array and hybrid capture 2: a split-sample study. BMC Cancer $2015 ; 15$.

17. Lillsunde Larsson G, Carlsson J, Karlsson MG, et al. Evaluation of HPV genotyping assays for archival clinical samples. J Mol Diagn 2015;17:293-301.

18. Bonde J, Rebolj M, Ejegod DM, et al. HPV prevalence and genotype distribution in a population-based split-sample study of well-screened women using CLART HPV2 human papillomavirus genotype microarray system. BMC Infect Dis 2014;14.

19. Lawson W, Schlecht NF, Brandwein-Gensler M. The role of the human papillomavirus in the pathogenesis of Schneiderian inverted papillomas: an analytic overview of the evidence. Head Neck Pathol 2008;2:49-59.

20. Sjö NC, von Buchwald C, Cassonnet $P$, et al. Human papillomavirus in normal conjunctival tissue and in conjunctival papilloma: types and frequencies in a large series. $\mathrm{Br} J$ Ophthalmol 2007:91:1014-5.

21. Buggage RR, Smith JA, Shen D, et al. Conjunctival papillomas caused by human papillomavirus type 33. Arch Ophthalmol 2002;120:202-4.

22. Saegusa M, Takano $\mathrm{Y}$, Hashimura M, et al. HPV type 16 in conjunctival and junctional papilloma, dysplasia, and squamous cell carcinoma. J Clin Pathol 1995;48:1106-10.

23. Zhao RW, Guo ZQ, Zhang RX. Human papillomavirus infection and the malignant transformation of sinonasal inverted papilloma: a meta-analysis. J Clin Virol 2016;79:36-43.

24. Syrjänen K, Syrjänen S. Detection of human papillomavirus in sinonasal papillomas: systematic review and meta-analysis. Laryngoscope 2013;123:181-92.

25. Re M, Gioacchini FM, Bajraktari A, et al. Malignant transformation of sinonasal inverted papilloma and related genetic alterations: a systematic review. Eur Arch Otorhinolaryngol 2017;274:2991-3000.

26. Eklund $\mathrm{C}$, Forslund $\mathrm{O}$, Wallin $\mathrm{KL}$, et al. Global improvement in genotyping of human papillomavirus DNA: the $2011 \mathrm{HPV}$ LabNet International Proficiency study. J Clin Microbiol 2014;52:449-59.

27. Eklund C, Forslund O, Wallin KL, et al. The 2010 global proficiency study of human papillomavirus genotyping in vaccinology. J Clin Microbio/ 2012;50:2289-98. 